\title{
Clinical utility of fecal calprotectin: potential applications beyond inflammatory bowel disease for the primary care physician
}

\author{
Amir Maria, Fadi Abu Bakerb, Mahmud Mahamida, Afif Yacoobc, Wisam Sbeit ${ }^{d}$, Tawfik Khoury ${ }^{d}$ \\ The Nazareth Hospital, EMMS, Nazareth, Israel, Faculty of Medicine in the Galilee, Bar-Ilan University, Safed, Israel; \\ Hillel Yaffe Medical Center, Hadera, Israel; Galilee Medical Center, Nahariya, Israel, Faculty of Medicine in the Galilee, \\ Bar-Ilan University, Safed, Israel; Rambam Healthcare Campus, Haifa, Israel
}

\section{Abstract}

\begin{abstract}
Fecal calprotectin (FC) is an inflammatory marker released mainly from gastrointestinal granulocytes measured in stool samples. FC is noninvasive, economical, simple, and acceptable for patients. Levels of FC have proven reliable for intestinal inflammation, with good clinical sensitivity, and are useful in screening and monitoring inflammatory bowel disease (IBD), as well as in the differential diagnosis between IBD and irritable bowel syndrome (IBS). Given its advantages, FC represents an attractive biomarker that could be utilized in various gastrointestinal (GI) diseases apart from IBD, and is currently being studied extensively by many research groups with significant amounts of data emerging. In this current review we aim to provide an outline of the utility of FC in distinguishing between IBS and IBD, as well as an up-to-date summary of the available clinical experience concerning FC in various common conditions of the GI tract commonly encountered by gastroenterology practitioners, such as IBS, microscopic colitis, acute gastroenteritis, Clostridium difficile infection, colorectal cancer, diverticular disease, coeliac disease, and other GI conditions.
\end{abstract}

Keywords Fecal calprotectin, potential clinical application, non-inflammatory bowel disease

Ann Gastroenterol 2019; 32 (5): 1-6

\section{Introduction}

Gastrointestinal (GI) complaints, such as abdominal pain, bloating, and diarrhea, are common symptoms in the general population and prevalent in the primary care setting, but may also be a presentation of various GI organic or functional diseases. Defining the underlying etiology is generally challenging and necessitates complementary diagnostic examinations, including blood tests, imaging, endoscopy and histology. The introduction of noninvasive diagnostic tools

${ }^{a}$ Gastroenterology and Endoscopy United, The Nazareth Hospital, EMMS, Nazareth, Israel, Faculty of Medicine in the Galilee, Bar-Ilan University, Safed, Israel; ' ${ }^{b}$ astroenterology Department, Hillel Yaffe Medical Center, Hadera, Israel; ' Department of Gastroenterology, Galilee Medical Center, Nahariya, Israel, Faculty of Medicine in the Galilee, Bar-Ilan University, Safed, Israel; dGastroenterology and Hepatology Department, Rambam Healthcare Campus, Haifa, Israel

Conflict of Interest: None

Correspondence to: Fadi Abu Baker, MD, Institute of Gastroenterology and Liver Diseases, Hillel Yaffe Medical Center, Hashalom St., Hadera, Israel, e-mail: Fa-fd@hotmail.com

Received 18 January 2019; accepted 1 April 2019; published online 20 June 2019

DOI: https://doi.org/10.20524/aog.2019.0394 into clinical practice has been invaluable in the assessment of various GI symptoms and may ultimately decrease the use of invasive, complicated, expensive and potentially harmful procedures, such as endoscopy. In the last decade new markers have been extensively investigated with the aim of identifying a universal marker that can be introduced into clinical practice for primary care physicians and gastroenterologists. Fecal calprotectin (FC) appears to be the best candidate, as testing for levels of this protein has high accuracy, reproducibility and practicality, the test is easy to perform, and the results are simple to interpret. $\mathrm{FC}$ is a protein heterodimer (A100A8/A9) released by granulocytes, monocytes, macrophages and epithelial cells during an inflammatory response [1,2], with inflammatory cells accumulating in the mucosa. FC is subsequently released in the stool, from where it can be measured using a commercially available enzymelinked immunosorbent assay, and it is resistant to metabolic degradation for up to 7 days at room temperature [3]. Roseth et al showed a good correlation between FC and the fecal excretion of indium-111-labeled granulocytes via scintigraphy in patients with inflammatory bowel disease (IBD) [4]. Several groups have investigated FC concentrations in healthy individuals and a cutoff of $50 \mu \mathrm{g} / \mathrm{g}$ for a positive test has been suggested, although a cutoff of $100 \mu \mathrm{g} / \mathrm{g}$ appears to have better accuracy for an IBD diagnosis [5], while factors such as type of assay and manufacturers' recommendations should also be 
considered. Several factors affect FC levels, including acute GI infections, colon adenomas and malignancies, non-steroidal anti-inflammatory drugs, and age, since children under the age of 5 years have been found to have higher FC concentrations, probably due to higher intestinal permeability [6].

In this review we aim to present a concise outline of the current clinical experience of FC in non-IBD conditions of the GI tract commonly faced by the primary care physician, such as irritable bowel syndrome (IBS), microscopic colitis (MC), acute gastroenteritis (AGE), Clostridium difficile (C. difficile) infection (CDI), colorectal cancer (CRC), diverticular disease (DD), and celiac disease (CD), together with less common GI conditions (Tables 1 and 2). The role of FC in diagnosing and monitoring IBD has been extensively studied in recent years and there is a large body of data available in the literature; however, that subject is beyond the focus of this current review.

\section{Role of FC in IBS}

IBS and IBD share common symptoms, such as abdominal pain and diarrhea, thereby making a differential diagnosis challenging in clinical practice. A major concern for clinicians is misdiagnosing an organic disease as a functional one. FC is a validated biomarker for distinguishing between organic and functional cases, thus reducing the need for invasive tests, with all their associated negative consequences for patient safety and health system resources. Several systematic reviews and metaanalyses evaluating the role of FC in distinguishing between IBS and IBD have been published over the last decade. Von Roon et al performed a meta-analysis of 30 studies that included 5983 subjects investigated for various GI symptoms, including abdominal pain and changes in bowel habits. FC testing in all patients revealed a significant difference, with the mean value being $219 \mu \mathrm{g} / \mathrm{g}$ higher for IBD patients $(\mathrm{P}<0.001)$. A cutoff value of $50 \mu \mathrm{g} / \mathrm{g}$ had a sensitivity of $95 \%$ and a specificity of $91 \%$ in distinguishing between IBD and non-IBD subjects [7]. Waugh et al conducted a meta-analysis of 28 studies that analyzed the role of FC in diverse situations. In 730 patients from 7 studies, FC levels allowed a distinction to be made between IBS and IBD, with a sensitivity of $93 \%$ and specificity of $94 \%$ for a $50 \mu \mathrm{g} / \mathrm{g}$ cutoff value [8]. Buri et al found that an FC level $>50 \mathrm{mg} / \mathrm{g}$ was capable of distinguishing between organic and non-organic GI conditions among 405 patients with heterogeneous gut symptoms who had been referred for colonoscopy, with a high sensitivity and specificity $(84.4 \%$ and $94.5 \%$, respectively) [9]. Similar results were also reported by Tibble et al in a study that included 602 patients with symptoms indicative of either IBS or IBD. FC levels in patients diagnosed with organic disease were found to be significantly higher than those in patients with non-organic disease, with a sensitivity and specificity of $89 \%$ and $79 \%$, respectively, while the sensitivity of a positive ROME questionnaire for IBS was $85 \%$ with a specificity of $71 \%$ [10]. A study by Langhorst et al revealed that FC was higher in patients with active colitis $(104 \mu \mathrm{g} / \mathrm{g})$ compared to subjects who were ultimately diagnosed with IBS $(19 \mu \mathrm{g} / \mathrm{g})$ [11]. Consequently, due to the validated diagnostic accuracy of FC in differentiating between IBD and IBS, many physicians use levels of FC in clinical practice to screen for IBD in patients with symptoms of IBS in order to reduce the use of unnecessary investigations [12].

Since IBS is a multifactorial disease, low-grade inflammation is emerging as a potential mechanism that contributes to the pathogenesis of the disease, particularly in the post-infectious IBS subgroup. Therefore, theoretically, the implementation of FC as a surrogate marker of intestinal inflammation could represent an attractive tool for identifying IBS patients who

Table 1 Major findings of FC in various gastrointestinal conditions

\begin{tabular}{|c|c|c|c|c|}
\hline Disease (Ref.) & Study type & $\begin{array}{l}\text { Cohort } \\
\text { size } \\
\text { (overall) }\end{array}$ & FC level $(\mu \mathrm{g} / \mathrm{g})$ & Comment \\
\hline $\mathrm{MC}[15,16]$ & Prospective case-control & $\begin{array}{c}(21) \\
13 \\
9 \\
12\end{array}$ & $\begin{array}{c}6.25(6.25-99) \\
80(6.25-1899) \\
26(6.25-340)\end{array}$ & Positive correlation with disease severity \\
\hline IBS [7] & Meta-analysis of 30 studies & 5983 & $\mathrm{FC}>50$ & Good tool to distinguish between IBS and IBD \\
\hline $\mathrm{DD}[26]$ & Prospective case-control & 195 & $>60$ & FC level is correlated with complicated DD \\
\hline $\begin{array}{l}\text { Acute gastroenteritis } \\
\text { [25-27] } \\
\text { - Controls } \\
\text { - Viral } \\
\text { gastroenteritis } \\
\text { - Bacterial } \\
\text { gastroenteritis }\end{array}$ & Prospective case-control & $\begin{array}{c}(107) \\
41 \\
32 \\
34\end{array}$ & $\begin{array}{l}49.3(8.8-131.1) \\
219(119-350.2) \\
26.5(14.9-55.1)\end{array}$ & $\begin{array}{l}<0.001 \\
\text { FC is higher with bacterial disease }\end{array}$ \\
\hline $\begin{array}{l}\text { CDI } \\
\text { - Mild }[23,24] \\
\text { - Severe }\end{array}$ & Case-control Prospective & $\begin{array}{l}50 \\
30\end{array}$ & $\begin{array}{c}188.2(41.4-591.6) \\
1391.5(173.5-2075.9)\end{array}$ & $\begin{array}{l}\text { Good correlation between severe CDI and } \\
\text { high FC }\end{array}$ \\
\hline
\end{tabular}

FC, fecal calprotectin; $M C$, microscopic colitis; IBS, irritable bowel syndrome; IBD, inflammatory bowel disease; DD, diverticular disease; CDI, Clostridium difficile infection 
Table 2 Summary of the studies reported on FC levels in in non-infectious gastrointestinal diseases

\begin{tabular}{|c|c|c|c|c|}
\hline Reference & Study type & $\begin{array}{c}\text { Cohort size } \\
\text { (overall) }\end{array}$ & FC level $(\mu \mathrm{g} / \mathrm{g})$ & P-value \\
\hline 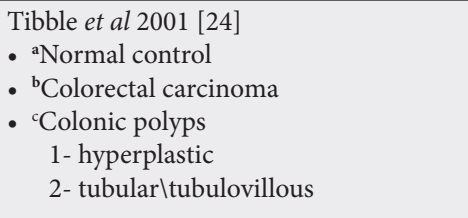 & $\begin{array}{l}\text { Prospective } \\
\text { case-control }\end{array}$ & $\begin{array}{c}(209) \\
96 \\
62 \\
51\end{array}$ & $\begin{array}{l}2.3 \mathrm{mg} / \mathrm{L} \\
101 \mathrm{mg} / \mathrm{L} \\
4.5 \mathrm{mg} / \mathrm{L} \\
12 \mathrm{mg} / \mathrm{L}\end{array}$ & $\begin{array}{l}<0.0001 \text { (a vs. b) } \\
0.003 \text { ( } 1 \text { vs. a) } \\
0.0003 \text { ( } 2 \text { vs. a) }\end{array}$ \\
\hline $\begin{array}{l}\text { Meucci et al } 2010 \text { [26] } \\
\text { - Inflammatory and neoplastic diseases } \\
\text { - Normal colonoscopy }\end{array}$ & Prospective & $\begin{array}{c}(870) \\
521 \\
349\end{array}$ & $\begin{array}{l}>50 \mathrm{mg} / \mathrm{dL} \\
<50 \mathrm{mg} / \mathrm{dL}\end{array}$ & $0.04-<0.0001$ \\
\hline 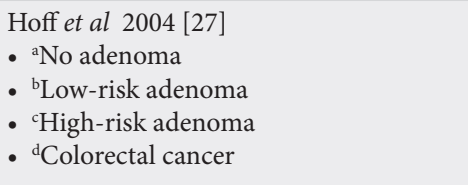 & Retrospective & $\begin{array}{c}(2311) \\
1518 \\
592 \\
185 \\
16\end{array}$ & $\begin{array}{l}55.2(15.6-2092.2) \\
46.7(15.6-772) \\
51.7(15.6-616.8) \\
156.5(15.6-1245)\end{array}$ & $\begin{array}{l}0.19 \text { (a vs. b vs. c) } \\
<0.05 \text { (d vs. a, b, c) }\end{array}$ \\
\hline 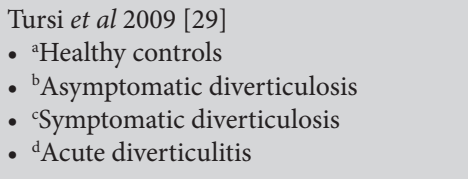 & $\begin{array}{l}\text { Prospective } \\
\text { case-control }\end{array}$ & $\begin{array}{l}(64) \\
16 \\
16 \\
16 \\
16\end{array}$ & $\begin{array}{l}<15 \\
<15 \\
>60 \\
>60\end{array}$ & $\begin{array}{l}\text { NS (a vs. b) } \\
<0.005 \text { (a vs. c) } \\
<0.0005 \text { (a vs. d }\end{array}$ \\
\hline $\begin{array}{l}\text { Montalto et al } 2007[30] \\
\text { - Healthy controls } \\
\text { - Untreated celiac disease }\end{array}$ & $\begin{array}{l}\text { Prospective } \\
\text { case-control }\end{array}$ & $\begin{array}{l}(58) \\
28 \\
30\end{array}$ & $\begin{array}{l}36.51 \\
45.02\end{array}$ & 0.163 \\
\hline $\begin{array}{l}\text { Balamtekin et al } 2012[31] \\
\text { - }{ }^{\mathrm{a}} \text { Healthy control } \\
\text { - }{ }^{\mathrm{b}} \text { Gluten free diet (Celiac patients) } \\
\text { - }{ }^{\mathrm{c}} \text { Newly diagnosed celiac disease }\end{array}$ & $\begin{array}{l}\text { Prospective } \\
\text { case-control }\end{array}$ & $\begin{array}{l}(98) \\
34 \\
33 \\
31\end{array}$ & $\begin{array}{c}9.6(1-70) \\
3.7(0.5-58.2) \\
117(3.2-306)\end{array}$ & $<0.001$ (c vs. a \& b) \\
\hline $\begin{array}{l}\text { Ertekin et al } 2010 \text { [32] } \\
\text { - }{ }^{\mathrm{a}} \text { Healthy control } \\
\text { - }{ }^{\mathrm{b}} \text { Newly diagnosed celiac disease } \\
\text { - }{ }^{\mathrm{c}} \text { Gluten free diet (Celiac patients) }\end{array}$ & $\begin{array}{l}\text { Prospective } \\
\text { case-control }\end{array}$ & $\begin{array}{c}(39) \\
10 \\
29 \\
\text { Included in the } 29 \text { patients }\end{array}$ & $\begin{array}{c}4.3 \mathrm{mg} / \mathrm{L} \\
13.4 \mathrm{mg} / \mathrm{L} \\
4.6 \mathrm{mg} / \mathrm{L}\end{array}$ & $\begin{array}{l}0.004 \text { (a vs. b) } \\
0.001 \text { (b vs. c) }\end{array}$ \\
\hline 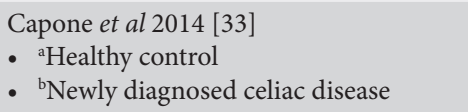 & $\begin{array}{l}\text { Prospective } \\
\text { case-control }\end{array}$ & $\begin{array}{c}(100) \\
50 \\
50\end{array}$ & $\begin{array}{l}45.1 \\
57.7\end{array}$ & NS \\
\hline
\end{tabular}

FC, fecal calprotectin

may benefit from anti-inflammatory therapy. However, a randomized controlled study by Lam et al that tested the effect of the anti-inflammatory drug mesalazine in IBS patients yielded negative results [13]. A recent prospective study of 93 patients with IBS by Melchior et al aimed to characterize patients with increased FC levels using different factors, such as age, sex, disease subtype and disease severity, as well as diagnostic workup findings, such as breath tests, distension as measured by a rectal barostat, and assessment of inflammation in colonic biopsies. FC levels were found to be higher in one third of patients, and age was the only factor that correlated with this patient group. No other associations to clinical phenotype or workup findings, including inflammation in colonic biopsies, were correlated with increased FC levels [14]. Taken together, these findings indicate that FC has an important role in distinguishing between IBD and IBS, although its role in identifying IBS patients who may benefit from anti-inflammatory therapy requires further randomized controlled studies. Furthermore, it is important to note that, in patients with a high FC level diagnosed with IBS, another cause other than IBS should be suspected. Importantly, the patient's clinical presentation and scenario are the most important parameters in decision making and diagnostic plan setting, especially when FC is only mildly elevated.

\section{Role of FC in MC}

MC is characterized clinically by watery diarrhea in old women and histopathologically by microscopic inflammation with abnormal sub-epithelial collagen deposition and lymphocyte infiltration. Generally, endoscopy shows a normal colon and biopsy is mandatory for establishing a diagnosis. The role of FC in MC was studied by Wildt et al in 21 patients with active MC, 12 patients with MC in remission, and 13 healthy 
subjects; the corresponding FC levels were $80 \mu \mathrm{g} / \mathrm{g}, 26 \mu \mathrm{g} / \mathrm{g}$ and $6.25 \mu \mathrm{g} / \mathrm{g}$, respectively [15]. Patients with active MC had significantly higher levels of FC compared with the remission and control groups ( $\mathrm{P}=0.025$ and $\mathrm{P}=0.02$, respectively). A more recent prospective study by Von Arnim et al measured FC levels in 23 patients with MC (16 in clinical remission and 7 with active disease) and compared the results to FC levels in patients with IBS. It was reported that FC levels were significantly higher in the active MC group compared with the remission and IBS groups $(\mathrm{P}<0.0001)[16]$.

The increased level of FC in MC is interesting because of the scarcity of neutrophils; however, FC could originate from macrophages and monocytes. Despite these results obtained to date, the role of FC in diagnosing and managing $\mathrm{MC}$ remains to be validated by future multicenter studies, although higher levels of FC appear to be a surrogate marker of active MC.

\section{Role of FC in AGE}

AGE is a prevalent clinical presentation in both the adult and pediatric populations in the primary care setting. Generally, these bouts of illness are self-limiting and do not require investigation or specific management. Nonetheless, some clinical scenarios-such as a severe clinical presentation and symptom onset in a hospitalized or immunocompromised patient, amongst others (high-risk patients) - may mandate evaluation, and in such cases it is critical to differentiate between viral and bacterial infections. Stool culture is considered the mainstay for diagnosing bacterial AGE, but the length of time needed to acquire the results and other practical limitations has led to other diagnostic tools being sought. The role of FC has been investigated in AGE and yielded some promising results. Shastry et al conducted a large prospective, multicenter study of 2383 patients who presented with AGE, with the aim of determining a correlation between bacterial AGE (diagnosed by stool culture) and FC levels. The results were impressive, with sensitivity and specificity of $83 \%$ and $87 \%$, respectively, for FC levels in diagnosing bacterial infections [17]. These results have also been confirmed in adult populations, where FC levels were found to be higher during a bacterial infection and were correlated with disease severity $[18,19]$. However, the role of FC in the management of AGE is limited by the acute and self-limited nature of these conditions and more research is needed to better address the utility of FC in identifying bacterial infection in high-risk patients.

\section{Role of FC in CDI}

C. difficile is a potentially dangerous pathogen that causes nosocomial and community-acquired diarrhea, and is generally associated with morbidity and mortality. Treatment outcomes are related to infection severity; consequently, an optimal severity assessment is crucial for optimizing therapy and achieving the best outcomes. Kim et al measured FC levels in 80 patients with acute CDI; 50 patients had mild CDI and 30 had severe CDI, based on the CDI severity assessment score developed by Zar et al [20], and the results were compared with those in a control group of 71 patients. FC levels were found to be significantly higher in patients with severe CDI compared to mild CDI $(\mathrm{P}<0.001)$ and to the control group $(\mathrm{P}<0.001)$, and the implementation of FC levels as a predictive marker for assessing CDI severity was proposed [21]. Peretz et al confirmed these results and noted an additional interesting finding that higher FC levels were associated with virulent ribotype 027 C. difficile strains [22].

\section{Role of FC in CRC}

The role of FC in CRC diagnosis and screening was first examined in 1993 by Roseth et al, who found that levels of FC were significantly higher in $94.3 \%$ of patients with CRC [23]. A later study in 2001 by Tibble et al compared FC levels to fecal occult blood tests in 62 patients with CRC and reported that the sensitivity and specificity of FC levels for CRC were $79 \%$ and $72 \%$, respectively [24]. A more recent study by a Hungarian group, who measured 5 biomarkers including FC in 95 patients with CRC, found a sensitivity of $77.8 \%$ and specificity of $70 \%$ for FC in the diagnosis of CRC [25]. However, 2 other studies have shown significantly lower sensitivity and specificity for FC in diagnosing CRC $[26,27]$. Therefore, the role of FC in $\mathrm{CRC}$ diagnosis and screening remains the subject of debate and requires further investigation, although CRC should be considered when there are GI symptoms accompanied by high FC levels.

\section{Role of FC in DD}

Given the inflammatory nature of DD and the lack of noninvasive biomarkers for diagnosing and monitoring the disease, FC is an attractive candidate warranting further investigation. Tursi et al measured FC levels in 48 patients with DD (16 with asymptomatic DD, 16 with symptomatic uncomplicated DD, and 16 with acute uncomplicated DD), and FC levels were compared to 16 IBS patients and 16 healthy controls. FC levels were found to be higher in patients with symptomatic uncomplicated DD $(\mathrm{P}<0.005)$, and in patients with acute uncomplicated diverticulitis $(\mathrm{P}<0.0005)$ compared with the healthy controls, IBS and asymptomatic DD patients. Moreover, when FC levels were assessed 8 weeks after treatment with mesalazine and rifaximin, they were completely normal in the groups with symptomatic uncomplicated DD and acute uncomplicated DD. It was concluded that FC levels may have a practical use in detecting inflammation and response to treatment in DD patients [28]. In addition, a further review study by Tursi et al found that FC $>60 \mu \mathrm{g} / \mathrm{g}$ was correlated with acute complications of DD [29]. 


\section{Role of FC in CD}

Few studies have assessed FC levels in adult and pediatric patients with $\mathrm{CD}$, and discordant results have been reported. Montalto et al measured FC levels in 28 adults with untreated CD and compared the results to FC levels in 30 healthy volunteers. Although FC levels were only slightly higher in CD patients compared with the healthy volunteers, a trend towards higher FC levels in CD was observed [30]. However, different results were obtained from a pediatric population in Turkey when 3 groups were studied: 31 children with untreated CD, 33 children with $\mathrm{CD}$ who adhered to a gluten-free diet, and 43 healthy controls. FC levels were found to be significantly higher in the untreated $\mathrm{CD}$ group compared to treated $\mathrm{CD}$ patients $(\mathrm{P}<0.001)$ and to the controls $(\mathrm{P}<0.001)$. An additional interesting finding was the significant decrease in FC levels reported after switching to a gluten-free diet in the untreated group $(\mathrm{P}<0.01)$. It was concluded that FC can assist in diagnosing $\mathrm{CD}$ and also in monitoring adherence to a gluten-free diet [31]. Another pediatric study by Ertiken et al found higher levels of FC in 29 newly diagnosed children with $\mathrm{CD}$ in comparison to 10 controls $(\mathrm{P}<0.04)$ [32]. Similarly, Capone et al measured FC concentrations in 50 newly diagnosed CD adults and compared the results to 50 controls. FC levels were examined in relation to clinical symptoms, histology findings and antibody levels for tissue transglutaminase, but a negative correlation was reported between FC levels and symptoms, histology and antibody levels; it was concluded that FC is irrelevant in CD workup and management [33]. Consequently, the role of FC in CD diagnosis and monitoring remains ambiguous, although $\mathrm{CD}$ should be considered as a cause of high FC levels in the pediatric population.

\section{Role of FC in other GI diseases}

The potential role of FC has been studied in many other GI conditions; however, most of these studies involved small numbers of patients and revealed inconclusive or contrary results. Levels of FC have been measured in patients with diarrhea following a hematopoietic stem cell transplant when they were suspected of developing GI graft versus host disease (GVHD), but contradictory results were reported by 2 different studies, although FC levels seemed to be higher in more advanced GVHD [34,35]. Pezzilli et al measured FC levels in patients with pancreatic disease, aiming to identify a possible link to intestinal inflammation, and found that $50 \%$ of the 20 patients with chronic pancreatitis had higher FC levels [36]. Khalid et al studied the potential of FC levels in diagnosing radiation enteritis in 59 patients undergoing pelvic radiotherapy for different malignancies. FC levels were measured at baseline and 5 weeks after treatment onset, but the increase was insignificant [37]. Raia et al studied the concentration of FC in 30 pediatric patients with cystic fibrosis; FC levels were reported to be significantly higher compared to controls $(\mathrm{P}<0.01)$ and significantly lower compared to 15 patients with IBD $(\mathrm{P}<0.001)$ [38]. Further studies have linked higher levels of FC to small intestinal bacterial overgrowth [39], food allergy, gastroesophageal reflux disease [40], hepatic encephalopathy in patients with liver cirrhosis [41], and iatrogenic causes, such as gastric bypass surgery [42].

\section{Concluding remarks}

Because of its positive attributes, the evaluation of FC as a biomarker in clinical practice for the diagnosis and monitoring of several GI disorders has yielded encouraging results. Its potential utilization is currently being investigated by many research groups from different fields and a significant body of data has emerged in recent years. Currently, the best available evidence in the literature supports its use in IBD diagnosis and monitoring, as well as in distinguishing between IBD and IBS. The increased level of FC in MC is interesting because of the scarcity of neutrophils. Despite these results obtained to date, the role of FC in diagnosing and managing MC remains to be validated by future multicenter studies, although higher levels of FC appear to be a surrogate marker of active MC. FC levels were found to be significantly higher in patients with severe CDI compared to mild CDI and to the control group, and the implementation of FC levels as a predictive marker for assessing and stratifying CDI severity has been proposed. FC levels may have a practical use in detecting inflammation and response to treatment in DD patients. In addition $\mathrm{FC}>60 \mu \mathrm{g} / \mathrm{g}$ was correlated with acute complications of DD. Knowledge is evolving concerning its potential application in various $\mathrm{GI}$ conditions, such as $\mathrm{CD}, \mathrm{CRC}$, GVHD and others, and further studies are required to address the many uncertainties which remain and to better define the use of FC levels in clinical practice.

\section{References}

1. Johne B, Fagerhol MK, Lyberg T, et al. Functional and clinical aspects of the myelomonocyte protein calprotectin. Mol Pathol 1997;50:113-123.

2. Nakashige TG, Zhang B, Krebs C, Nolan EM. Human calprotectin is an iron-sequestering host-defense protein. Nat Chem Biol 2015; 11:765-771.

3. Røseth AG, Fagerhol MK, Aadland E, Schjønsby H. Assessment of the neutrophil dominating protein calprotectin in feces. A methodologic study. Scand J Gastroenterol 1992;27:793-798.

4. Røseth AG, Schmidt PN, Fagerhol MK. Correlation between faecal excretion of indium-111-labelled granulocytes and calprotectin, a granulocyte marker protein, in patients with inflammatory bowel disease. Scand J Gastroenterol 1999;34:50-54.

5. Konikoff MR, Denson LA. Role of fecal calprotectin as a biomarker of intestinal inflammation in inflammatory bowel disease. Inflamm Bowel Dis 2006;12:524-534.

6. Rugtveit J, Fagerhol MK. Age-dependent variations in fecal calprotectin concentrations in children. $J$ Pediatr Gastroenterol Nutr 2002;34:323-324.

7. von Roon AC, Karamountzos L, Purkayastha S, et al. Diagnostic precision of fecal calprotectin for inflammatory bowel disease and colorectal malignancy. Am J Gastroenterol 2007;102:803-813. 
8. Waugh N, Cummins E, Royle P, et al. Faecal calprotectin testing for differentiating amongst inflammatory and non-inflammatory bowel diseases: systematic review and economic evaluation. Health Technol Assess 2013;17:xv-xix, 1-211.

9. Burri E, Manz M, Rothen C, Rossi L, Beglinger C, Lehmann FS. Monoclonal antibody testing for fecal calprotectin is superior to polyclonal testing of fecal calprotectin and lactoferrin to identify organic intestinal disease in patients with abdominal discomfort. Clin Chim Acta 2013;416:41-47.

10. Tibble JA, Sigthorsson G, Foster R, Forgacs I, Bjarnason I. Use of surrogate markers of inflammation and Rome criteria to distinguish organic from nonorganic intestinal disease. Gastroenterology 2002;123:450-460.

11. Langhorst J, Junge A, Rueffer A, et al. Elevated human betadefensin-2 levels indicate an activation of the innate immune system in patients with irritable bowel syndrome. Am J Gastroenterol 2009;104:404-410.

12. Furman DL, Cash BD. The role of diagnostic testing in irritable bowel syndrome. Gastroenterol Clin North Am 2011;40:105-119.

13. Lam C, Tan W, Leighton M, et al. A mechanistic multicentre, parallel group, randomised placebo-controlled trial of mesalazine for the treatment of IBS with diarrhoea (IBS-D). Gut 2016;65:91-99.

14. Melchior C, Aziz M, Aubry T, et al. Does calprotectin level identify a subgroup among patients suffering from irritable bowel syndrome? Results of a prospective study. United European Gastroenterol J 2017;5:261-269.

15. Wildt S, Nordgaard-Lassen I, Bendtsen F, Rumessen JJ. Metabolic and inflammatory faecal markers in collagenous colitis. Eur $J$ Gastroenterol Hepatol 2007;19:567-574.

16. von Arnim U, Wex T, Ganzert C, Schulz C, Malfertheiner P. Fecal calprotectin: a marker for clinical differentiation of microscopic colitis and irritable bowel syndrome. Clin Exp Gastroenterol 2016;9:97-103.

17. Shastri YM, Bergis D, Povse N, et al. Prospective multicenter study evaluating fecal calprotectin in adult acute bacterial diarrhea. Am J Med 2008;121:1099-1106.

18. Chen CC, Huang JL, Chang CJ, Kong MS. Fecal calprotectin as a correlative marker in clinical severity of infectious diarrhea and usefulness in evaluating bacterial or viral pathogens in children. J Pediatr Gastroenterol Nutr 2012;55:541-547.

19. Sýkora J, Siala K, Huml M, Varvařovská J, Schwarz J, Pomahačová R. Evaluation of faecal calprotectin as a valuable non-invasive marker in distinguishing gut pathogens in young children with acute gastroenteritis. Acta Paediatr 2010;99:1389-1395.

20. Zar FA, Bakkanagari SR, Moorthi KM, Davis MB. A comparison of vancomycin and metronidazole for the treatment of Clostridium difficile-associated diarrhea, stratified by disease severity. Clin Infect Dis 2007;45:302-307.

21. Kim J, Kim H, Oh HJ, et al. Fecal calprotectin level reflects the severity of Clostridium difficile infection. Ann Lab Med 2017;37:53-57.

22. Peretz A, Tkhawkho L, Pastukh N, Brodsky D, Halevi CN, Nitzan O. Correlation between fecal calprotectin levels, disease severity and the hypervirulent ribotype 027 strain in patients with Clostridium difficile infection. BMC Infect Dis 2016;16:309.

23. Roseth AG, Kristinsson J, Fagerhol MK, et al. Faecal calprotectin: a novel test for the diagnosis of colorectal cancer? Scand J Gastroenterol 1993;28:1073-1076.

24. Tibble J, Sigthorsson G, Foster R, Sherwood R, Fagerhol M, Bjarnason I. Faecal calprotectin and faecal occult blood tests in the diagnosis of colorectal carcinoma and adenoma. Gut 2001;49:402-408.
25. Rutka M, Bor R, Bálint A, et al. Diagnostic accuracy of five different fecal markers for the detection of precancerous and cancerous lesions of the colorectum. Mediators Inflamm 2016;2016:2492081.

26. Meucci G, D'Incà R, Maieron R, et al. Diagnostic value of faecal calprotectin in unselected outpatients referred for colonoscopy: A multicenter prospective study. Dig Liver Dis 2010;42:191-195.

27. Hoff G, Grotmol T, Thiis-Evensen E, Bretthauer M, Gondal G, Vatn MH. Testing for faecal calprotectin (PhiCal) in the Norwegian Colorectal Cancer Prevention trial on flexible sigmoidoscopy screening: comparison with an immunochemical test for occult blood (FlexSure OBT). Gut 2004;53:1329-1333.

28. Tursi A, Brandimarte G, Elisei W, Giorgetti GM, Inchingolo CD, Aiello F. Faecal calprotectin in colonic diverticular disease: a casecontrol study. Int J Colorectal Dis 2009;24:49-55.

29. Tursi A. Biomarkers in diverticular diseases of the colon. Dig Dis 2012;30:12-18.

30. Montalto M, Santoro L, Curigliano V, et al. Faecal calprotectin concentrations in untreated coeliac patients. Scand J Gastroenterol 2007;42:957-961.

31. Balamtekın N, Baysoy G, Uslu N, et al. Fecal calprotectin concentration is increased in children with celiac disease: relation with histopathological findings. Turk $J$ Gastroenterol 2012;23:503-508.

32. Ertekin V, Selimoğlu MA, Turgut A, Bakan N. Fecal calprotectin concentration in celiac disease. J Clin Gastroenterol 2010;44:544-546.

33. Capone P, Rispo A, Imperatore N, Caporaso N, Tortora R. Fecal calprotectin in coeliac disease. World $J$ Gastroenterol 2014;20:611-612.

34. Rodriguez-Otero P, Porcher R, Peffault de Latour R, et al. Fecal calprotectin and alpha- 1 antitrypsin predict severity and response to corticosteroids in gastrointestinal graft-versus-host disease. Blood 2012;119:5909-5917.

35. Chiusolo P, Metafuni E, Giammarco S, et al. Role of fecal calprotectin as biomarker of gastrointestinal GVHD after allogeneic stem cell transplantation. Blood 2012;120:4443-4444.

36. Pezzilli R, Barassi A, Morselli-Labate AM, et al. Fecal calprotectin and elastase 1 determinations in patients with pancreatic diseases: a possible link between pancreatic insufficiency and intestinal inflammation. J Gastroenterol 2007;42:754-760.

37. Khalid U, McGough C, Hackett C, et al. A modified inflammatory bowel disease questionnaire and the Vaizey Incontinence questionnaire are more sensitive measures of acute gastrointestinal toxicity during pelvic radiotherapy than RTOG grading. Int $J$ Radiat Oncol Biol Phys 2006;64:1432-1441.

38. Raia V, Maiuri L, de Ritis G, et al. Evidence of chronic inflammation in morphologically normal small intestine of cystic fibrosis patients. Pediatr Res 2000;47:344-350.

39. David L, Babin A, Picos A, Dumitrascu DL. Small intestinal bacterial overgrowth is associated with intestinal inflammation in the irritable bowel syndrome. Clujul Med 2014;87:163-165.

40. Berni Canani R, Rapacciuolo L, Romano MT, et al. Diagnostic value of faecal calprotectin in paediatric gastroenterology clinical practice. Dig Liver Dis 2004;36:467-470.

41. Gundling F, Schmidtler F, Hapfelmeier A, et al. Fecal calprotectin is a useful screening parameter for hepatic encephalopathy and spontaneous bacterial peritonitis in cirrhosis. Liver Int 2011;31:1406-1415.

42. Boerlage TC, Westerink F, Poland DC, Huibregtse IL, Acherman YI, Gerdes VE. Fecal calprotectin, elastase, and alpha-1-antitrypsin levels after roux-en- $Y$ gastric bypass; calprotectin is significantly elevated in the majority of patients. Obes Surg 2016;26:2974-2980. 